\title{
THE ANALYSIS OF WORD FORMATION PROCESSES IN THE JAKARTA POST WEBSITE
}

\author{
Dian Luthfiyati ${ }^{1}$ \\ Islamic University of Lamongan \\ Abdul Kholiq ${ }^{2}$ \\ Islamic University of Lamongan \\ Intan Ni'matus Zahroh ${ }^{3}$ \\ Islamic University of Lamongan \\ dian.luthfiyati@gmail.com ${ }^{1}$
}

Submit, 07-11-2017 Accepted, 30-12-2017 Publish, 30-12-2017

\begin{abstract}
A new language and term use new words that we can relate to the one of linguistics branches of the morphological aspect namely word formation process. The process of word formation in creation of new English words is called derivation. One of the language phenomenon is in the practice of language used in online news specifically Jakarta Post Website. The Jakarta Post is one of the daily Indonesian has language English. The Jakarta post presented with various of news, such as sport, entertainment, education, etc. The purpose of this study is identifying the most common type of derivation words that is used in the headline of ten education articles in "Jakarta Post Website" in October 2015 until April 2016. This study uses qualitative method. The result show that the most common of derivation words that is used in headline ten article educations in 'Jakarta Post Website' in October 2015 until April 2016 is noun derivations.
\end{abstract}

Keywords: derivation, jakarta post.

\section{INTRODUCTION}

Morphology has encouraged some researchers to conduct research related to morphological study. According to Haspelmath and Sims (2010:2) morphology is the study of word formation, including the ways new words are coined in the languages of the world. The way forms of words are varied depending on how we are used in sentences. We must have knowledge about how to form new words. We also recognize and understand new words that we never heard before. As the language develops every time, there are new languages and terms emerge day by day in the society. A new language and term use new words that we can relate to the one of linguistics branches of the morphological aspect namely word 
formation process. In the process of word formation, there are exploring some of the basic processes by which new words are created such as derivation, prefixes and suffixes, etc. According to Yule (2005:57) the process of word formation in creation of new English words, this process is called derivation.

One of the language phenomenons is in the practice of language used in online news, Jakarta Post Website. The Jakarta Post is one of the daily Indonesian which is using English language. The Jakarta post presented with various of news, such as sport, entertainment, education, etc.

On online news, language is used as communication between writer and the reader. Online news is verbal descriptions and written material, including articles, journal, and etc. Online news is also introduces the reader to these cultural and linguistic concepts. Because it is natural sources of meaning linguistic and cultural news. There are many derivations words that we should know.

Morphology refers to the branch of linguistics that deals with words, their internal structure, and how they are formed. According to Haspelmath and Sims (2010:3) Linguists often describe alternations with a special set of morphological rules, which were historically phonetically motivated, but affect morphology.

Morphological analysis typically consists of the identification of parts of words or more technically, constituents of words. According to Haspelmath and Sims (2010:1) morphology is the study of the internal structure of words. Somewhat paradoxically, morphology is both the oldest and one of the youngest sub disciplines of grammar. It is the oldest because, as far as we know, the first linguists were primarily morphologists.

For example, we can say that the word nuts consists of two constituents: the element nut and the element $s$. In accordance with a widespread typographical convention, we will often separate word constituents by a hyphen: nut-s. It is often suggested that morphological analysis primarily consists in breaking up words into their parts and establishing the rules that govern the co-occurrence of these parts. The smallest meaningful constituents of words that can be identified are called morphemes. In nut-s, both $-s$ and nut are morphemes. Other examples of words consisting of two morphemes would be breaking, hope-less, re-write, cheese-board; words consisting of three morphemes are re-writ-ing, hope-lessness, ear-plug-s; etc (Haspelmath and Sims, 2010:3).

Linguists define a morpheme as the smallest unit of language that has its own meaning. Simple words like giraffe, wiggle, or yellow are morphemes, but so are prefixes like re-and pre- and suffixes like -ize and -er. There are far more to be said about morphemes but for now we can use the term morpheme to help us come up with a more precise and coherent definition of word ( Aronoff and Fudeman, 2011:2).

Morphemes have two types for English word. There are free morphemes and bound morphemes. Free A free morpheme is one that can stand on its own that is, it's an entire word. Examples the, cat, run, pretty, trapezoid free morphemes may appear with other bound morphemes attached to them, crucially, though they don't need to have other morphemes on them. A bound morpheme cannot stand on its own, but rather must be attached to a free morpheme whenever you say it. Examples re-, un-, -est, -er, -fer. 
Some morphemes are roots, others are affixes. According to Aronoff and Fudeman (2011:2) a root is like a stem in constituting the core of the word to which other pieces attach, but the term refers only to morphologically simple units. Root The primary piece of meaning in a word, to which affixes can be added. In English, a root is often a word itself.

For example, now consider the word reconsideration. We can break it into three morphemes: re-, consider, and -ation. Consider is called the stem. A stem is a base unit to which another morphological piece is attached. The stem can be simple, made up of only one part, or complex, itself made up of more than one piece. Here it is best to consider consider a simple stem. Although it consists historically of more than one part, most present-day speakers would treat it as an unanalyzable form. We could also call consider the root.

Word formation is specifically formed words with the certain processes. According to Yule (2006:53-59) defines word formation processes as a way of forming and creating new words from the use of old words. It is stated that there many types of word formation processes. There are coinage, borrowing, compounding, blending, clipping, backformation, conversion, acronym, derivation, prefix and suffix, and multiple processes.

In the process of word formation, there are explore some of the basic processes by which new words are created specifically for derivation. According to Yule (2006:57) derivation is the process of word formation to be found in the production of new English word. The process of word formation through the addition affix (suffix), which can be either a prefix (prefix) or suffix (suffix). For example of the addition prefix as like asleep for a+ sleep, rewrite for re+write, incorrect for in+correct. And the addition of the suffix as like importance for import + ance as the suffix, enjoyment for enjoy+ment, happiness for happy+ness.

All english words formed by derivational process have either prefix or suffix, or both. But according to Haspelmath \& Sims (2010:87-89) stated, there are too many types of derivational meaning to present here, but it is worth discussing one frequent characteristic of derivation. Derivational patterns commonly change the word-class of the base lexeme - i.e. nouns can be derived from verbs, adjectives from nouns, and so on.

\section{Adjective Derivation}

Derived adjectives are even less common than derived verbs, because adjectives are used more rarely than verbs, let alone nouns.e.g changeable from the word change and able form of suffix. Friendly from the word friend and ly form of suffix.

\section{Noun Derivation}

Noun formed from the process of the formation of derivative, which the result from noun will have different meaning of basic word e.g imagination from the word imagine and nation form of suffix. Novelist from the word novel and ist form of suffix. 


\section{Verb Derivation}

Verb-deriving patterns are generally less numerous and diverse. Most commonly, verbs are derived from other verbs e.g walked from the word walk and -ed of suffix. Enclose from the word close and en form of prefix.

From that phenomenon, the writer try to find out the derivation that used in Jakarta Post website especially in 10 article about education that published in October 2015 until April 2016. Besides that, the writer also find the most common of derivation that used. This study focused in the headline. The writer is interested in conducting this research because morphology as the ways to know variety of new words that use of language in world. It is very important to understand about derivations process that occurs in online news as communication media.

\section{RESEARCH METHOD}

The researcher use a qualitative research method, which means the data will be analyzed qualitatively. The researcher as the key instrument because the researcher himself collected, described and analyzing the data found from only education headline ten articles in Jakarta Post Website in October 2015 until April 2016. There are four data collecting technique: the first, the researcher will read the source of the data, the second, the researcher select the selected article of headlines, then the data are written on table that has been supplied and the last is the data encountered are then classified in accordance with the appropriate category. After collecting the data, the researcher analyzes the data. There are four activities to analyze data: The researcher read the Headlines of article education, the researcher chosen by identifying the kinds of derivations in some Headlines of article education in Jakarta post online, the researcher underlined the word that which included Derivations, the data are analyzed and quantify results on the data table.

\section{FINDING}

From the data and analysis, the writer found 17 adjective derivation words. 26 noun derivation words and 9 verb derivation words and total all of the derivation are 52 words. First article, there are 2 adjective derivation, 5 words noun derivation and not verb derivation. Second article, there are 1 word adjective derivation, 2 words noun derivation, and not verb derivation. The third article, there are 4 words adjective derivation, 3 words noun derivation and not verb derivation. The fourth article, there are 1 word adjective derivation, 1 word noun derivation, and 1 verb derivation. Fifth article, there are 1 word adjective derivation, 1 word noun derivation, and 1 verb derivation. Sixth article, there are 1 word adjective derivation, 1 word noun derivation, and 3 words verb derivation. 
Seventh article, there are 3 words adjective derivation, 1 word noun derivation, and 1 word verb derivation. From eighth article, there are 1 word adjective derivation, 4 words noun derivation and 1 verb derivation. Ninth article, there are 1 word adjective derivation, 4 words noun derivation, and not derivation and the last from tenth article, there are 2 words adjective derivation, 4 words noun derivation and 2 verb derivation.

\section{DISCUSSION}

The result of this research showed that there were derivation words in the headline of ten education articles in 'Jakarta Post Website" in October 2015 until April 2016 as follow:

\section{Adjective Derivation}

- Adjective+ suffix

The writer finds adjective maker suffixes for example:

-ful (successful),

-ary (elementary, secondary),

-ive (interactive, attractive),

$-y$ (lengthy),

-ly (orderly),

-al (critical, vocational),

-ical (technological),

-er (younger),

-ant (important),

-ed (skilled),

- Adjective + affix

The writer finds adjective maker affixes for example:

- un (unchecked, unreliable, unforeseen)

\section{Noun Derivation}

- Noun + suffix

In noun suffix, the writer finds the suffixes for example:

-ion (education, migration, location, invitation),

-ive (relative),

-ence (dependence, attendance, existence, conference),

-ness (weakness, business, uniqueness, competitiveness, illness),

-ity (responsibility, opportunity, reality),

-ion (publication, allocation),

-ation (foundation),

-ian (politician),

-ment (imprisonment, government),

-ery (fishery),

-ency (fluency), 
-ism (humanism),

-ing (thinking)

\section{Verb Derivation}

- Verb+ affix

In verb affix, the writer finds the affix for example:

-en (encourage)

- Verb+suffix

The writer finds verb maker suffixes for example:

-ed (offered, aimed, welcomed, explained),

-ize (memorize),

-ing (implementing, fishing, shaping)

Table 1. Total Derivations Word in the Jakarta Post Website

\begin{tabular}{|c|c|c|c|}
\hline No. & Data & Type of derivations & Total \\
\hline \multirow{3}{*}{1.} & \multirow{3}{*}{ I } & Adjective derivations & 2 words \\
\hline & & Noun Derivations & 5 words \\
\hline & & Verb Derivations & - \\
\hline \multirow{3}{*}{2.} & \multirow{3}{*}{ II } & Adjective derivations & 1 Word \\
\hline & & Noun Derivations & 2 words \\
\hline & & Verb Derivations & - \\
\hline \multirow{3}{*}{3.} & \multirow{3}{*}{ III } & Adjective derivations & 4 word \\
\hline & & Noun Derivations & 3 words \\
\hline & & Verb Derivations & - \\
\hline \multirow{3}{*}{4.} & \multirow{3}{*}{ IV } & Adjective derivations & 1 word \\
\hline & & Noun Derivations & 1 word \\
\hline & & Verb Derivations & 1 word \\
\hline \multirow{3}{*}{5.} & \multirow{3}{*}{ V } & Adjective derivations & 1 word \\
\hline & & Noun Derivations & 1 word \\
\hline & & Verb Derivations & 1 word \\
\hline \multirow{3}{*}{6.} & \multirow{3}{*}{ VI } & Adjective derivations & 1 word \\
\hline & & Noun Derivations & 1 word \\
\hline & & Verb Derivations & 3 words \\
\hline \multirow{3}{*}{7.} & \multirow{3}{*}{ VII } & Adjective derivations & 3 words \\
\hline & & Noun Derivations & 1 word \\
\hline & & Verb Derivations & 1 word \\
\hline \multirow{3}{*}{8.} & \multirow{3}{*}{ VIII } & Adjective derivations & 1 Word \\
\hline & & Noun Derivations & 4 words \\
\hline & & Verb Derivations & 1 word \\
\hline
\end{tabular}




\begin{tabular}{cccc}
\hline 9. & & Adjective derivations & 1 word \\
& IX & Noun Derivations & 4 words \\
Verb Derivations & - \\
\hline \multirow{3}{*}{10.} & Adjective derivations & 2 Words \\
& & Noun Derivations & 4 words \\
& & Verb Derivations & 2 words \\
\hline & & 52 words \\
\hline
\end{tabular}

This section discusses the research findings in relation to the problem on the most common of derivation words that is used in Headline education articles "Jakarta Post Website" in October 2015 until April 2016 that is noun derivation. The verb derivation is seldom used in content of article. This process of the derivation is from base word and the addition prefix and suffix.

\section{CONCLUSION}

Based on the research conducted in headline of ten articles Jakarta Post Website October 2015 until April 2016, it can be concluded that the new words which are formed through derivation process from the base word with addition of affix and suffix or both. Actually, many characteristic of derivation process such as noun can be derived from verb, adjective from noun, and many other but the writer find among 52 derivation words with three kinds of derivation process 17 words included of adjective derivation, 26 words included of noun derivation, and 9 words included of verb derivation, so that the writer tries to find the most common of derivation words that is used headline of ten article education in "Jakarta Post Website" in October 2015 until April 2016, that is noun derivation and verb derivation is seldom used in content of article.

\section{REFERENCES}

Aronoff, M., \& Fudeman, K. (2011). What Is Morphology?, second edition. India: Blackwell Publishing Ltd.

Haspelmath, M., \& Sims A,D. (2010). Understanding Morphology, second edition. London: Hodder Education,an Hachette UK Company,338 Euston Road.

Lieber, R. (2009). Introducing Morphology. New York: Cambridge University Press.

Sugiyono.(2013). Metode Penelitian Pendidikan Pendekatan Kuantitatif, kualitatif, dan $R \& D$. Bandung: Alfabeta.

Yule, G. (2006). The Study of Language, third edition. New York: Cambridge University Pres 